\title{
Construindo um novo curso em Saúde Pública para o ensino de graduação do terceiro ano médico da Faculdade de Medicina de Botucatu
}

\author{
Building a new Public Health discipline to the medical undergraduation \\ course of the College of Medicine, Botucatu/Unesp
}

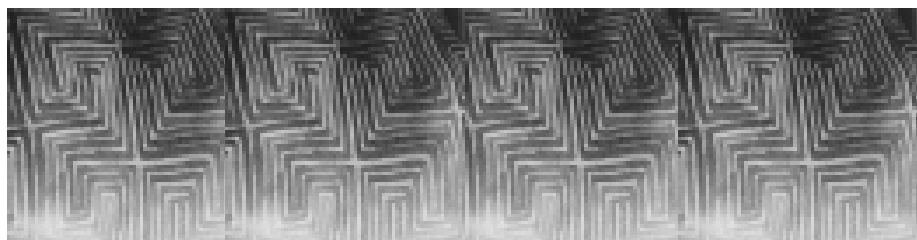

Em 1997 um novo currículo foi implantado na Faculdade de Medicina de Botucatu. Os docentes do Departamento de Saíde Pública (DSP) envolveram-se neste projeto de reformulação curricular, propondo-se a integrar, rever e reestruturar disciplinas $e$ contribuir para a formulação de um plano de integração Universidade, Serviço Local de Saúde e Comunidade (Projeto UNI-Botucatu), acreditando na possibilidade de mudança. Em 1998, um grupo de docentes do DSP iniciou a construção de um novo curso - Saúde Coletiva III - a ser ministrado ao terceiro ano da graduação médica com a participação de cinco disciplinas: Administração em Saúde Pública, Ciências Sociais, Epidemiologia, Ética $e$ Nutrição em Saúde Pública. Este curso foi oferecido pela primeira vez em 1999, organizado sob três núcleos temáticos: Problemas em Saúde Pública; Nutrição em Saúde Pública; Planejamento em Saúde. Todo o processo de construção do curso foi realizado coletivamente, com a participação de nove professores envolvidos na formulação, desenvolvimento e execução inicial do mesmo, avaliando-se experiências anteriores como: ensino fragmentado, aulas essencialmente expositivas, desvalorização do conteúdo por estudantes. O modelo de ensino centrou-se na problematização de situações concretas vivenciadas na prática da Saúde Pública, trabalhando em áreas de abrangência de Centros de Saúde do Município de Botucatu, Serviços e Organizações de Saúde da região e em sala de aula, estimulando a capacidade de argumentação dos estudantes. Privilegiou-se o trabalho em pequenos grupos, com orientação docente.

O objetivo desta tese foi descrever e avaliar o primeiro ano de implantação do curso Saúde Coletiva III, propondo apresentar os ajustes necessários para sua continuidade.

$\mathrm{Na}$ descrição do curso foram utilizados roteiros de aula, anotações, textos, relatórios, diários de classe e atas de reunião de professores. Para avaliação do curso trabalhou-se com: A) a avaliação do estudante utilizando-se dois instrumentos: 1) um questionário fechado sobre qualidade de ensino e do desempenho dos professores (modificado de SEEQ: Students' Evaluation of Educational Quality) com escala de 5 pontos (de muito ruim a muito bom) contendo os seguintes itens: aprendizado e valores; entusiasmo dos professores; organização do curso; interação em grupo; conteúdo; $e$ aspectos gerais. Ao término de cada núcleo temático o questionário foi entregue aos 81 alunos do curso; 2) ao final do curso todos os estudantes receberam um questionário com questões abertas sobre os maiores problemas, os aspectos mais relevantes e propostas/ 
sugestões para continuidade do curso, além da solicitação de elaboração de uma carta de apresentação do curso aos alunos que o estariam cursando no ano seguinte; B) a autoavaliação dos professores com relação aos itens: capacitação docente, desempenho, facilidades e dificuldades para atuar neste curso e aproveitamento do mesmo no desempenho de outras atividades profissionais.

Os três núcleos temáticos foram estruturados como módulos separados, havendo, no entanto, uma preocupação de se estabelecer pontes de relações entre os mesmos. A turma foi dividida em nove grupos, cada qual com nove alunos e um professor orientador. A avaliação foi uma constante preocupação no curso. Na avaliação dos estudantes dois terços consideraram bons o aprendizado e o processo de desenvolvimento do curso; dois terços deles consideraram muito bom ou bom o padrão de envolvimento dos professores; sobre a interação em grupo, três quartos dos alunos a avaliaram como boa ou muito boa, principalmente em relação à participação ativa nas discussões em grupo. De todos os aspectos estudados, o primeiro núcleo temático - Problemas em Saúde Pública - foi o mais bem avaliado, apresentando as maiores pontuações. Os professores e os estudantes valorizaram a metodologia do curso, a oportunidade de trabalharem em grupo na forma realizada e a importância de um contato tão próximo do professor orientador. $\mathrm{O}$ trabalho de conhecimento $e$ vivência no Sistema Único de Saúde, SUS, também foi valorizado, ligando-o à possibilidade de, com o uso da metodologia do planejamento estratégico (bastante enfatizado no curso), procurar-se não só conhecer a realidade, como também buscar estratégias para enfrentá-la. Foi considerado um entrave, por alunos e professores, a excessiva substituição dos docentes, por reconhecerem que os substitutos não estavam adequadamente capacitados ou mesmo não conheciam profundamente a proposta do curso.

Pode-se observar que, se por um lado, a formulação deste curso é resultado de uma proposta ampla de reformulação curricular ocorrida na Faculdade de Medicina de Botucatu nos anos que o antecederam, chegada a hora de executá-lo, a reformulação curricular já estava em curso, porém a mesma não se efetivou da maneira como havia sido proposta. Desta forma, esta primeira concepção de Curso de Saúde Coletiva, dado de forma única, integrando disciplinas ou ainda tornando-as um único curso ocorreu muito mais por um esforço interno do Departamento de Saúde Pública do que pela proposta geral de reformulação curricular da instituição. Disto decorre a percepção de um alto grau de autonomia $e$ independência dos formuladores do curso no sentido de "abrirem asas a imaginação" e formularem um curso de acordo com seus princípios básicos de Saúde Coletiva, Ética e usos de metodologias educacionais, sem a necessidade de discussão

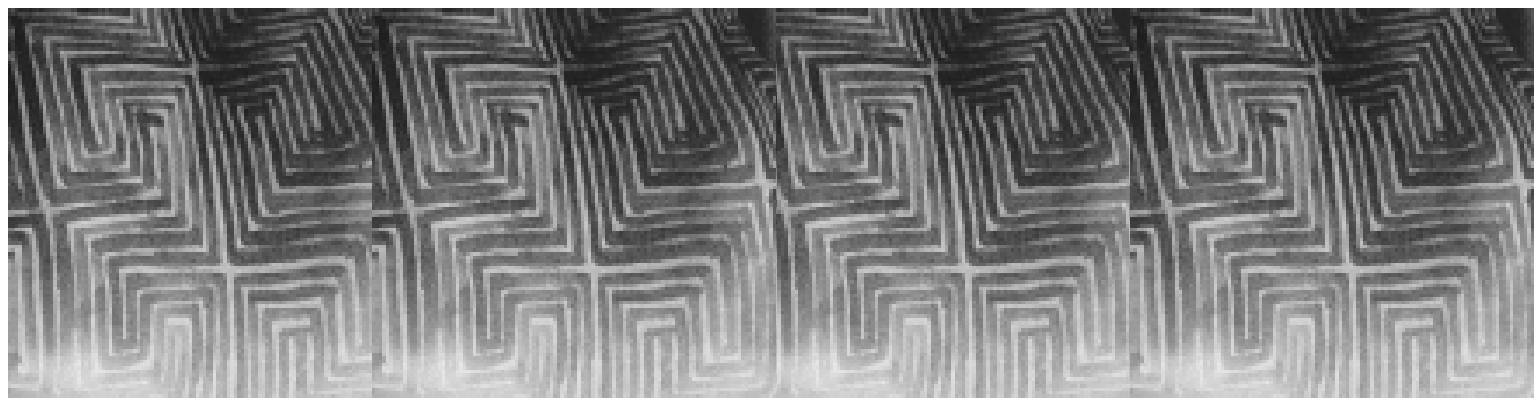


de cada passo com a instituição.

A formulação do curso num intenso processo de discussão, durante sua execução, permitiu uma revisão contínua das proposições previstas inicialmente. Foi possível ainda constatar que, dado todo o trabalho exigido do docente, na instituição, não seria possível manter o mesmo grupo de professores durante todo o curso e, neste sentido, trabalhou-se para encontrar novos professores e capacitá-los da melhor forma possível. Esta questão aparece como um problema tanto na fala dos alunos como na dos professores e para o futuro deve ser mais bem avaliada, pois, na condução do curso, isto gerou insegurança para todos. Todos os núcleos temáticos foram bem avaliados pelos alunos, notando-se que o aprendizado na percepção dos estudantes foi adequado. No entanto, há de se refletir sobre a percepção de que, no geral, o primeiro foi o mais bem avaliado e, se comparado aos demais, pode-se notar que foi havendo uma queda no sentido do muito bom e bom para bom e regular. Isto pode ser explicado pelo fato de o primeiro grupo de professores estar mais capacitado para ministrar o curso, já que se tratava de seus formuladores. A principal missão colocada aos formuladores deste curso voltou- se à percepção de utilização de estratégias que pudessem proporcionar ao estudante de Medicina a valorização do campo da Saúde Coletiva, como um importante componente da educação médica. No entanto, o contexto geral vivenciado no Brasil dificulta esta aspiração, já que a todo momento só são apresentadas, principalmente na mídia, as falhas, o "caos", em que se encontra o SUS, inclusive na Atenção Primária à Saúde. Como o curso valorizou o trabalho no SUS, e em especial na atenção primária, o que foi reconhecido $e$ valorizado pelos estudantes, talvez este seja um dos pontos mais fortes enquanto resultados objetivados e alcançados pelo curso. Uma das questões mais gratificantes $e$ entusiasmantes deste curso, para os alunos $e$ professores, foi o trabalho com novas tecnologias.

Com estas ponderações e com a necessidade de revisão e melhor organização futura é preciso salientar que participar do curso gerou a percepção da possibilidade de mudança de ensino $e$ a expectativa de também poder contaminar a instituição com nossos êxitos.

Eliana Goldfarb Cyrino Tese de Mestrado, 2000 Department of Medical Education University of Illinois at Chicago

PALAVRAS-CHAVE: ensino médico; currículo; inovação metodológica. KEYWORDS: medical education; curriculum; methodological innovation. PALABRAS-CLAVE: educación medica; curriculum; innovación metodologica. 